\title{
Microstructural changes and void swelling of a 12Cr ODS ferritic-martensitic alloy after high-dpa self-ion irradiation
}

\author{
Tianyi Chen ${ }^{\mathrm{a}}$, EdaAydogan ${ }^{\mathrm{b}}$, Jonathan G. Gigax ${ }^{\mathrm{a}}$, Di Chen ${ }^{\mathrm{a}}$, Jing Wang ${ }^{\mathrm{b}}$, XuemeiWang ${ }^{\mathrm{a}}$, S. \\ Ukai $^{\mathrm{c}}$, F. A. Garner ${ }^{\mathrm{a}, \mathrm{d}}$, Lin Shao ${ }^{\mathrm{a}, *}$
}

${ }^{a}$ Department of Nuclear Engineering, Texas A\&M University, TX 77843

${ }^{b}$ Department of Material Science and Engineering, Texas A\&M University, TX 77843

${ }^{c}$ Department of Material Science and Engineering, Hokkaido University: N13, W-8,Kita-ku, Sapporo 060-0808, Japan

${ }^{d}$ Radiation Effects Consulting, Richland, WA 99354

\begin{abstract}
A dual-phase $12 \mathrm{Cr}$ oxide-dispersion-strengthened (ODS) alloy, with improved corrosion and oxidation resistance exhibits promising void swelling resistance and microstructural stability under $\mathrm{Fe}^{2+}$ ion irradiation to $800 \mathrm{dpa}$ at $475 \circ \mathrm{C}$. Dispersoids were originally present in both ferrite and tempered martensite grains, with the latter having a wider range of dispersoid sizes. In both phases dispersoids> $10 \mathrm{~nm}$ in diameter are incoherent with the matrix, while smaller dispersoids are coherent. During irradiation the larger incoherent dispersoids shrank and disappeared. Beyond 60 dpadispersoids in both phases approached a near-identical equilibrium size of $\sim 2-2.5 \mathrm{~nm}$, which appears to be rather independent of local displacement rate. Grain morphology was found to be stable under irradiation. Compared to other ferritic-martensitic alloys, the ion-induced swelling of this alloy is quite low, arising from swelling resistance associated with both tempered martensite and dispersoids in both phases, with the swelling in tempered martensite being an order of magnitude less than in the ferrite phase.
\end{abstract}

Keywords:ODS, dual-phase, Ferritic-martensitic, coherency, ion irradiation, void swelling, microstructure stability, nano-particle

* Corresponding author. Tel.: +1 979845 4107; fax: +1 979845 6443. E-mail address: 


\section{Ishao@tamu.edu (L.Shao).}

\section{Introduction}

Ferritic-martensitic (F/M) alloys are known to have greater resistance to void swelling, higher thermal conductivities and lower thermal expansion coefficients than do austenitic alloys [1-5]. The strength and swelling resistance of F/M alloys can be further improved by adding fine dispersions of various yttria oxides [6-10]. The majority of such oxide-dispersion-strengthened (ODS) alloys introduce dispersoids in ferrite phases [11-18]. However, previous studies have shown that in the absence of dispersoids, the ferrite phase is significantly less swelling resistant than the tempered martensite phase, as tested using neutron irradiation and heavy-ion irradiation [5,19]. The tempered martensite phase is usually smaller in grain size compared with ferrite, and has more dense and complex internal microstructure to serve as sinks for point defects created by radiation, thereby imparting additional resistance to void nucleation. Therefore, it has been suggested that employing dispersoids in the tempered martensite phase may gain additional swelling-suppression, first by pinning the grain walls to maintain small grain size and second by allowing the dispersoids to serve as sinks. To date, however, very limited results have been reported on ODS tempered martensite phase [7-9, 20, 21]. Among them, a $9 \mathrm{Cr}$ ODS tempered martensite alloy was reported to have promising swelling resistance, improved strength, but exhibited complicated dispersoid dissolution behavior under irradiation using a rastered ion beam [7-9, 20], in spite of the fact that beam rastering is known to suppress void nucleation and growth [22-24].

Recently, a novel 12Cr ODS dual-phase F/M alloy involving dispersoids in both ferrite and tempered martensite phase was developed to obtain superior corrosion and high-temperature oxidation resistance $[25,26]$. This dual-phase alloy has a majority of tempered martensite phase and a minority of ferrite, at a ratio of $\sim 4: 1$. The amount of ferrite phase, consisting of thermally equilibrium ferrite and residual ferrite, was optimized at $\sim 20 \%$ to enhance its creep rupture strength $[6,26,27]$. In this work, microstructures of this $12 \mathrm{Cr}$ dual-phase ODS were characterized before and after ion irradiation to very high displacements per atom (dpa) values using a defocused non-rastered beam. Defocusing beams were used since they better resemble reactor neutron damage, compared to pulsed beams that suppress void swelling [23, 24]. The 
radiation response of dispersoids in both ferrite and tempered martensite were studied separately, providing information to guide the next steps of material development toward a stronger radiation tolerance of $\mathrm{F} / \mathrm{M}$ alloys.

\section{Experiment procedures}

The composition of the $12 \mathrm{Cr}$ ODS dual-phase F/M alloy is provided in table 1. Elemental powders were mechanically alloyed in an argon gas atmosphere and consolidated at $1100{ }^{\circ} \mathrm{C}$ for 2 hours. The consolidated specimens were then hot-extruded at $1150{ }^{\circ} \mathrm{C}$, normalized at $1050{ }^{\circ} \mathrm{C}$ for 1 hour before tempering at $800{ }^{\circ} \mathrm{C}$ for 1 hour. More extensive details of alloy synthesis have been reported by Ukaiet. al [26].

Specimens were cut to dimensions of $5 \mathrm{~mm} \times 5 \mathrm{~mm} \times 0.7 \mathrm{~mm}$ and then mechanically polished with SiC paper, progressing down to a grit of 1200 , followed by $0.05 \mu \mathrm{m}$ aluminum powder. The surface layer containing residual mechanical damage was then removed using electrical polishing with a perchloric solution. Irradiation with $3.5 \mathrm{MeV} \mathrm{Fe}{ }^{2+}$ ions was performed using a 1.7 MeV Tandetron accelerator. A defocused beam was used to avoid void-swellingsuppression characteristic of rastered beams [22-24]. The beam current was controlled at $200 \pm$ $10 \mathrm{nA}$, producing a maximum dpa rate of $\sim 1.74 \times 10^{-3} \mathrm{dpa}$ per second at damage peak. The depth profiles of dpa and injected Fe atoms, calculated by the SRIM code [28], are shown in Fig. 1. A value of $40 \mathrm{eV}$ displacement threshold energy and the Kinchin-Pease option were used for the damage calculations $[29,30]$. The irradiation temperature was controlled to be $475 \pm 10$ ${ }^{\circ} \mathrm{C}$ to maximize swelling based on previous determinations of peak swelling temperatures [25, 31-33]. The chamber vacuum during irradiation was better than $1 \times 10^{-6}$ torr.

Six specimens received 100, 200, 300, 400, 700 and 800 dpa at the peak displacement depth. Cross-sectional lamella samples from unirradiated and irradiated specimens were prepared using the focused-ion-beam (FIB) lift-out technique for transmission electron microscopy (TEM). TEM characterizations were performed using a 200 keVTechnai F20 Supertwin microscope. 


\section{Results}

\subsection{Characterization of unirradiated sample}

Figure 2 shows typical TEM micrographs of a ferrite grain (Figs. 2a-b) and a tempered martensite grain (Figs. 2c-d) observed in the as-received unirradiated sample. The ferrite grain fraction was measured to be $\sim 20 \%$. As pointed out by Ukaiet. al, the ferrite phase in this alloy consists of both residual ferrite and thermal equilibrium ferrite. While they arise from different mechanisms, these phases have essentially the same physical properties [26]. In addition, transformed ferrite can also exist when the phase transformation from austenite to ferrite takes place during air cooling [6]. Differences in grain size between ferrite and tempered martensite grains were obvious; ferrite grains were significantly larger (up to $\sim 1 \mu \mathrm{m}$ ) compared to tempered martensite grains $(\sim 200 \mathrm{~nm})$.

Tempered martensite and ferrite grains were found to have different dispersoid distributions. As shown in Fig $2 b$, dispersoids in one ferrite grain are more uniform in size and more homogeneously distributed. In contrast, dispersoids in tempered martensite phase as shown in Fig $2 \mathrm{~d}$ have large size variation even within one grain. The difference is statistically compared in Fig. 3, which was generated by measuring at least 100 randomly picked dispersoids from multiple grains in each of the ferrite and tempered martensite phases. The tempered martensite phase exhibits coarser dispersoids compared to the ferrite phase. In ferrite, while most dispersoids have diameter less than $5 \mathrm{~nm}$, larger dispersoids were found in the transformed ferrite. Similar coarse distributions of dispersoids in tempered martensite and transformed ferrite phases were also observed in $9 \mathrm{Cr}$ and other $12 \mathrm{Cr}$ ODS [8, 26, 34]. It has been suggested that the disturbance of interfacial coherency between dispersoid and matrix, during phase transformation, results in the coarsening of dispersoids via interfacial energy minimization $[6,27,35]$. Therefore fine dispersoids were more likely to exhibit coherency with the matrix than larger dispersoids. In both phases, the dispersoid density varies significantly from grain to grain. The average dispersoiddensity in tempered martensite and ferrite phases were measured to be $\sim 6 \times 10^{16} \mathrm{~cm}^{-3}$ and $\sim 1.6 \times 10^{17} \mathrm{~cm}^{-3}$, respectively. Energy-dispersive X-ray spectroscopy (EDS) analysis of dispersoids of sizes ranging from $\sim 3 \mathrm{~nm}$ to $\sim 30 \mathrm{~nm}$ in diameter showed an yttrium-titanium ratio (Y/Ti) of between $\sim 1: 1$ and $\sim 2: 1$. 
Figure. 4 shows bright field and weak beam dark field TEM micrographs of a tempered martensite grain. Dislocations and dispersoids have a non-uniform distribution and wide range in size. The dark field micrograph suggests that a coherent or semi-coherent relationship exists between most of the fine dispersoids and the matrix, as illustrated by the dashed arrow, while coarse dispersoids do not exhibit coherency, as illustrated by the solid arrow. This conclusion was later confirmed using high resolution TEM (HRTEM).

Figure 5 shows diffraction patterns and HRTEM micrographs of a $\sim 3 \mathrm{~nm}$ dispersoid in a ferrite grain imaged at the $[012]_{\alpha}$ zone axis. The diffraction pattern in Fig. 5a shows coherency between dispersoids and the matrix, which are confirmed by HRTEM images in Figs. 5b-d. As marked by dashed lines in Fig. 5b, the nano-particle exhibited two planar directions clearly visible. The two plane-to-plane distances were measured to be $0.24 \mathrm{~nm}$, and the angle between them was measured be to $61^{\circ}$. These agree with the $0.23 \mathrm{~nm}$ interplanar distance and $61.73^{\circ}$ inter-direction angle of (331) and (31 $\overline{3})$ planes of $\mathrm{Y}_{2} \mathrm{Ti}_{2} \mathrm{O}_{7}$, suggesting a coherency of $(32 \overline{1})_{d} \|(001)_{\alpha}$ and $[5 \overline{6} 3]_{d} \|[012]_{\alpha}$ between fine dispersoids and the ferrite matrix.

Figure. 6 shows diffraction patterns and HRTEM taken at $[011]_{\alpha}$ zone axes of a tempered martensite grain. Weak diffraction spots shown in Fig. 6a indicate that lattice coherency between fine dispersoids and the matrix exists, similar to fine dispersoids in ferrite phase. Figures. 6b-d correspond to a dispersoid with a diameter of $\sim 6 \mathrm{~nm}$. As shown in Figs. 6b-c, the coherency between the dispersoid and matrix is different from that of finer dispersoids. Two interplanarspacings were measured to be $0.28 \mathrm{~nm}$ and $0.27 \mathrm{~nm}$ with an angle of $86^{\circ}$ between them, matching the (330) and (221) planes of orthorhombic $\mathrm{Y}_{2} \mathrm{TiO}_{5}$. Therefore interface coherency of $(151)_{d} \|(011)_{\alpha}$ and $[114]_{d} \|[011]_{\alpha}$ is suggested. For dispersoids larger than $10 \mathrm{~nm}$ in diameter, no coherency was observed.

\subsection{Dispersoid shrinkage and stability}

Figures 7a-d were obtained from the 400 peak dpa sample, presented as a panoramic TEM micrograph showing dispersoids starting from the irradiated surface to a depth beyond the peak 
damage (the dpa peak is located at $\sim 1000 \mathrm{~nm}$ ). Only grains of the tempered martensite phase are shown in Fig. 7d. Both depth (bottom) and the corresponding local dpa values (top) are provided. The enlarged TEM images of three local regions correspond to the near-surface region, the half peak-dpa region and the end of damage region, respectively. In comparison with the bulk unirradiated region, overall, dispersoid sizes within the irradiated region are reduced. Similar observations have been reported in previous studies on $\mathrm{Ni}^{2+}$ ion irradiated 9Cr ODS and 14YWT, whereas rastered beams were used $[8,36]$. In addition, as shown in Figs. 7b-c, the highly irradiated region (in Fig. 7b) shows higher dispersoid density compared to regions receiving lower dpa (in Fig. 7c). Compared to unirradiated samples, the dispersoid density in tempered martensite was observed to increase due to irradiation by a factor of $\sim 1.5$.

The mean dispersoid sizes in samples after 100, 200, 400 and 800 peak dpa irradiation are plotted as a function of depth from irradiated surface in Fig. 8. The solid lines denote the size range of dispersoid distribution in unirradiated tempered martensite grains, and the dash lines denote the range of dispersoid sizes in unirradiated ferrite grains. One important finding is that dispersoid sizes were reduced after irradiation and approached to $\sim 2-2.5 \mathrm{~nm}$ in irradiated region ( $\leq 1000 \mathrm{~nm}$ ), regardless of different dpa rates at different depths.

Figure 9a shows two neighboring ferrite and tempered martensite grains at $\sim 750$ dpa region in the 800 peak dpa irradiated sample. Figures 9b-c are higher-magnification TEM micrographs showing dispersoids in the ferrite and tempered martensite grains, respectively. Figure.9d summarize size distributions of dispersoid in two phases after irradiation. Dispersoids in tempered martensite grains underwent a dramatic shrinkage. In both phases, most, if not all, dispersoids larger than $5 \mathrm{~nm}$ were removed by irradiation. In the ferrite phase, while there was a barely noticeable size change in the fine dispersoids, the dispersoid density dropped $\sim 20 \%$. Decrease in density and sustainment in size of the fine dispersoids in ferrite phase agrees with observations in neutron irradiated MA957 [13,37], while loss of larger dispersoids in the tempered martensite phase agrees with previous studies by Allen, et al. on Ni irradiated $9 \mathrm{Cr}$ ODS [8]. It is important that in the present study, dispersoids of different sizes were confirmed to have different stability in the same dual-phase alloy. 
Beyond $1200 \mathrm{~nm}$, where the dpa level rapidly drops to zero, a plateau of dispersoid diameter appears at $\sim 4-5 \mathrm{~nm}$, a range close to the mean dispersoid diameter in the pre-irradiation condition. The dispersoid size distribution in the radiation-free zone is the same as it is in preirradiation condition, suggesting that observed size difference in the irradiated region results from irradiation effects, instead of thermal annealing effects.

To further illustrate the evolution of dispersoid populations with increasing damage level, an analysis of dispersoid size was carried out, limited to the $400 \mathrm{~nm}$ to $700 \mathrm{~nm}$ depth range, to minimize compositional changes resulting from the injected Fe atoms. The selected region corresponds to a damage level of $\sim 60 \%$ of the peak dpa. Only tempered martensite data were used for this comparison. Figure. 10 shows that dispersoid shrinkage after ion irradiation essentially stops by $60 \mathrm{dpa}$; with a stable size distribution maintained thereafter. As pointed out in earlier studies, such stability of fine dispersoids can sustains ODS strength during irradiation $[8,10,38]$.

\subsection{Grain stability}

Figures 11a-e show bright field cross-sectional TEM micrographs of the unirradiated sample and samples irradiated to 100, 200, 400 and 800 peak dpa, respectively. The dashed lines in Fig. 11 refer to the $\sim 1 \mu \mathrm{m}$ region that was irradiated. Deeper regions represent structures that were thermally annealed but not irradiated. Note that the sample receiving 800 peak dpa was annealed at $475 \circ \mathrm{C}$ for as long as $\sim 125$ hours. No changes of grain size were noticed for both ferrite and tempered martensite phases in either the irradiated or thermally aged regions. Statistics of grain size are listed in Table 2. Compared to unirradiated samples, all grain sizes were maintained within the statistical standard deviance.

\subsection{Void swelling}

As shown in Fig. 9a, the ferrite and tempered martensite phases exhibit different swelling behavior under irradiation. In the depth of $550-800 \mathrm{~nm}$, faceted voids up to $45 \mathrm{~nm}$ in diameter formed in the larger central ferritic grain; while no voids were observed in the surrounding tempered martensite grains. Figures 12a-c show void formation in ferrite phase and Figs. 12d-f 
show void formation in tempered martensite phases as a function of dose. Micrographs were taken with an under-focus of $\sim 500 \mathrm{~nm}$ to image very small voids. Faceted voids were observed in ferrite phase at doses as low as $50 \mathrm{dpa}$. The void size increases with increasing dpa values. In comparison, only nano-cavities were observed in tempered martensite phase. Since void numbers in ferrite phase are quite limited, we focused on statistic analysis of voids in martensite phase only. Figures. 12g-i plot the void size distributions at 50, 200, and 400 local dpa regions, respectively. With increasing dpa values, void sizes gradually increase but are still limited to only a few nanometers only. At $400 \mathrm{dpa}$, for instance, the mean size is $\sim 1.4 \mathrm{~nm}$.

Figures. 13a and b compare the depth-dependent swelling in ferrite and tempered martensite phases, respectively. The "spikiness" of the swelling distribution results from low statistics when void numbers are limited. Overall, the swelling in ferrite is more than one order of magnitude higher than that in tempered martensite. Note, however, that while the peak dpa occurs at a depth of $\sim 1000 \mathrm{~nm}$ from the surface, the swelling at higher dpa levels disappears at $\sim 800 \mathrm{~nm}$, which is a well-known behavior attributed to combined effects from defect imbalance and the injected interstitial $[39,40]$. This behavior has been frequently observed in self-ion irradiated pure iron and other F/M steels [24, 29, 40].

\section{Discussion}

The $12 \mathrm{Cr}$ dual-phase ODS alloy appears to have a very good swelling resistance under the highdpa ion irradiation conditions employed in this study. Figure 14 plots the largest swelling values observed in the ferrite phase, as a function of local dpa where the data were extracted. These data are compared with published data from MA957, an ODS ferrite alloy [11], but this is not a single variable comparison due to differences in irradiating ion, energy and dpa rate. Nevertheless, this figure shows the rather low swelling obtained in the alloy of this study. Even more importantly, the majority of tempered martensite phase in this alloy is swelling almost negligibly, producing a very low overall swelling.

The swelling rate of ferrite phase in this ODS at the highest dpa examined was estimated to be $\sim 0.005 \% / \mathrm{dpa}$, significantly lower than the steady-state swelling rate of $\sim 0.2 \% / \mathrm{dpa}$ from neutron irradiation of Fe-Cr alloys reported by Garner et al. [3,33], and the $\sim 0.12 \% /$ dpa steady- 
state swelling rate shown in a recent study of $\alpha$-Fe under self-ion irradiation [24]. This suggested that the incubation period before onset of steady-state swelling has not yet been reached in the $12 \mathrm{Cr}$ dual-phase alloy $[11,33]$. The tempered martensite phase is known to have an even longer incubation period under ion irradiation, as observed in the two-phase alloy EM12 and EP$450[5,19,32]$.

In Fig. 15, we schematically show the understanding of the effects of dispersoids on void swelling and mechanical strength. The strong resistance to void swelling probably arises from a combination of factors. First, presence of fine grain structures with high boundary area is thought to provide defect trapping and annihilation sites [4, 11,41,42]. Higher densities of internal boundaries characteristic of tempered martensite may be critical to the swelling resistance. The fine grain structure and internal boundaries are also known to elevate hardness in F/M steels or F/M based ODS alloys [43]. The stability of grain sizes observed in this study suggests that both swelling resistance and hardness can persist to very high irradiation, possibly as a consequence of dispersoid locking and stabilizing of grain walls. Although there is larger swelling in the ferrite grains, a trade-off between swelling resistance and strength and ductility was made by optimizing composition, heat treatment and dispersoid volume and size [26]. In ferrite grains, dispersoids are finer with a higher density. As suggested by Ukai, such ultra finedispersoids lead to enhanced hardness, creep rupture strength and tensile strength [6]. On the other hand, tempered martensite grains having larger dispersoid and larger dispersoid distance are likely to be less hard compared to ferrite. The ferrite grains surrounding tempered martensite grains are critical to maintaining the appropriate creep rupture strength.

Second, the finely distributed dispersoids of high density appear to have enhanced the swelling resistance, probably by playing two roles, stabilizing grain structures and trapping of defects. Previous studies showed that fine dispersoids suppress growth and recrystallization of grains [44] and phase transformations [26,34]. The drag force applied to boundaries by dispersoids has been found to be stronger for finer size dispersoids [26, 34, 45]. In addition, as reported by Allen, et al. high-density dislocation segments were observed in a 9Cr ODS alloy both before and after irradiation $[9,46]$. Dispersoids were suggested to immobilize dislocations 
both within the grain and on the boundary walls, thereby preventing dislocation recovery under high-temperature irradiation $[9,46]$. On the other hand, the interface between dispersoids and the matrix has been reported to serve as defect recombination sites [9, 11, 47]. In a spherical $200 \mathrm{~nm}$ tempered martensite grain with dispersoid distribution reported earlier, the ratio of dispersoidmatrix interface to grain boundary area would be approximately $7 \%$ before irradiation, which is reduced to half after irradiation, due to the loss of dispersoid. Without evaluating the defect trap strength of dispersoid-matrix interface, the dominating surface area of grain boundary in tempered martensite suggests its more important role in swelling resistance.

During irradiation, the loss of the less-frequent, larger dispersoids in the alloy of this study is insufficient to overcome the much higher density of small dispersoids, especially since the lost yttria volume appears to be partially compensated by the increased density of smaller dispersoids in tempered martensite.

The shrinkage in dispersoid size suggests the operation of a ballistic dissolution mechanism but the quickly reached equilibrium size suggests the presence of rather strong healing by reprecipitation processes. Notably, the equilibrium dispersoid size was not strongly correlated to the local dpa rate, indicating the strong influence of these healing mechanisms. This may be due in part to the strong insolubility of yttrium in the presence of excess oxygen.

Diffusion mechanisms are believed to influence the changes in dispersoid size under irradiation. Based on Russell's radiation-affected precipitation model of equilibrium phases $[8,48]$, it is expected that large dispersoids would shrink and small dispersoids would grow under irradiation, although large precipitates in this scenario would fall to the equilibrium size and not disappear altogether, as was observed in this study. Russell's model predicts that the equilibrium size would be dependent on dpa rate, a phenomenon which was not observed in the present study. In addition, no coherency was observed for dispersoids larger than $\sim 10 \mathrm{~nm}$ in diameter and these larger dispersoids disappeared after irradiation, suggesting a correlation between dispersoid-matrix coherency and dispersoid stability. As another evidence of this correlation, dispersoids in both phases were observed to maintain coherency relationships with the matrix after irradiation, as observed in this study and others [37,49]. Further studies are needed on the radiation response of dispersoids at different temperatures and under different dpa 
rates, in order to understand the mechanisms in determining the irradiation-stable size and structures of dispersoids. Focuses should be put on interface structural configuration and interface energy differences of dispersoids having different sizes, as well as atomic scale details of how interfaces interact with point defects.

\section{Conclusions}

High dpa $\mathrm{Fe}^{2+}$ ion irradiations up to 800 peak dpa were conducted on a dual-phase 12Cr ODS at $475^{\circ} \mathrm{C}$. The alloy is very stable under irradiation with grain structures that were not significantly affected by radiation. During irradiation, dispersoids were found to reach to an equilibrium size and to change in density, while larger incoherent particles were destroyed. The equilibrium size, which was independent of dpa rate, was reached at as low as $60 \mathrm{dpa}$ and was preserved to the highest irradiation level in this study. Dispersoids in ferrite grains were initially very close to the equilibrium size and therefore showed better irradiation stability than dispersoids in tempered martensite grains. There appears to be a correlation between coherency and dispersoid stability. Void swelling was found to be much higher in ferrite grains than in tempered martensite grains, but overall the alloy was rather resistant to void swelling.

\section{Acknowledgement}

The research was supported by US Department of Energy, NEUP program, through grant no. DE-NE0008297. The authors acknowledge the Microscopy and Imaging Center (MIC) and Materials Characterization Facility (MCF) of Texas A\&M University for instruments access.

\section{References}

[1] F.A. Garner, in: Chapter 6 "Irradiation performance of cladding and structural steels in liquid metal reactors", volume 10A, Materials Science and Technology: A Comprehensive Treatment, VCH Publishers, 1994, pp. 419-543.

[2] R.L. Klueh, A.T. Nelson, Journal of Nuclear Materials 371 (2007) 37-52.

[3] B.H. Sencer, F.A. Garner, Journal of Nuclear Materials 283-287 (2000) 164-168. 
[4] A.M. Dvoriashin, S.I. Porollo, Yu. V. Konobeev, F.A. Garner, Journal of Nuclear Materials 329-333 (2004) 319-323.

[5] F.A. Garner, L. Shao, M.B. Toloczko, S.A. Maloy, V.N. Voyevodin, in: 17th International conference on environmental degradation of materials in nuclear power systems - water reactors, Ottawa, Ontario, Canada, Aug. 9-13, 2015.

[6] S. Ukai, S. Ohtsuka, Energy Materials 2 (2007).

[7] S. Ohtsuka, S. Ukai, M. Fujiwara, T. Kaito, T. Narita, Materials Transactions 46 (2005) 487-492.

[8] T.R. Allen, J. Gan, J.I. Cole, M.K. Miller, J.T. Busby, S. Shutthanandan, S. Thevuthasan, Journal of Nuclear Materials 375 (2008) 26-37.

[9] J. Gan, T.R. Allen, B.C. Birtcher, S. Shutthanandan, S. Thevuthasan, JOM 60 (2008) 2428.

[10] K. Mo, Z. Zhou, Y. Miao, D. Yun, H.-M. Tung, G. Zhang, W. Chen, J. Almer, J.F. Stubbins, Journal of Nuclear Materials 455 (2014) 376-381.

[11] M.B. Toloczko, F.A. Garner, V.N. Voyevodin, V.V. Bryk, O.V. Borodin, V.V. Mel'nychenko, A.S. Kalchenko, Journal of Nuclear Materials 453 (2014) 323-333.

[12] D.A. McClintock, D.T. Hoelzer, M.A. Sokolov, R.K. Nanstad, Journal of Nuclear Materials 386-388 (2009) 307-311.

[13] S. Yamashita, N. Akasaka, S. Ukai, S. Ohnuki, Journal of Nuclear Materials 367-370 (2007) 202-207.

[14] M.K. Miller, K.F. Russell, D.T. Hoelzer, Journal of Nuclear Materials 351 (2006) 261268.

[15] S. Yamashita, S. Ohtsuka, N. Akasaka, S. Ukai, S. Ohnuki, Philosophical Magazine Letters 84 (2004) 525-529.

[16] L.L. Hsiung, M.J. Fluss, A. Kimura, Materials letters 64 (2010) 1782-1785.

[17] L.L. Hsiung, M.J. Fluss, S. Tumey, J. Kuntz, B. El-Dasher, M. Wall, B. Choi, A. Kimura, F. Willaime, Y. Serruys, Journal of Nuclear Materials 409 (2011) 72-79. 
[18] S.K. Karak, J.D. Majumdar, Z. Witczak, W. Lojkowski, L. Ciupinski, K.J. Kurzydlowski, I. Manna, Metallurgical and Materials Transactions A 44A (2013) 2884-2894.

[19] P. Dubuisson, D. Gilbon, J.L. S_ran, Journal of Nuclear Materials 205 (1993) 178-189.

[20] A.G. Certain, K.G. Field, T.R. Allen, M.K. Miller, J. Bentley, J.T. Busby, Journal of Nuclear Materials 407 (2010) 2-9.

[21] R. Schäublin, A. Ramar, N. Baluc, V. de Castro, M.A. Monge, T. Leguey, N. Schmid, C. Bonjour, Journal of Nuclear Materials 351 (2006) 247-260.

[22] G.S. Was, Fundamentals of radiation materials science: metals and alloys, Springer, 2007.

[23] ASTM E521-83, Standard practice for neutron radiation damage simulation by chargedparticle irradiation, volume 12.02, ASTM International, 2009.

[24] J. Gigax, E. Aydogan, T. Chen, D. Chen, Y. Wu, W.Y. Lo, Y. Yang, F.A. Garner, Journal of Nuclear Materials 465 (2015) 343-348.

[25] R.L. Klueh, D.R. Harries, High-chromium ferritic and martensitic steels for nuclear applications, ASTM International, West Conshohocken, PA, 2001.

[26] S. Ukai, Y. Kudo, X. Wu, N. Oono, S. Hayashi, S. Ohtsuka, T. Kaito, Journal of Nuclear Materials 455 (2014) 700-703.

[27] S. Ukai, Metal, ceramic and polymeric composites for various uses, ISBN 978-953-307353-8, InTech, 2011.

[28] J.F. Ziegler, J.P. Biersack, 2013, SRIM program. URL: http://www.srim.org/.

[29] L.R. Greenwood, R.K. Smither, SPECTER: neutron damage calculations for materials irradiations, Technical Report ANL/FPP/TM-197, Argonne National Laboratory, Lemont, IL, 1985.

[30] R.E. Stoller, M.B. Toloczko, G.S. Was, A.G. Certain, S. Dwaraknath, F.A. Garner, Nuclear Instruments and Methods in Physics Research B 310 (2013) 75-80.

[31] F.A. Smidt Jr., P.R. Malmberg, J.A. Sprague, J.E. Westmoreland, Swelling behavior of commercial ferritic alloys, EM-12 and HT-9, as assessed by heavy ion bombardment, volume STP 611, ASTM International, Philadelphia, PA, 1976, pp. 227-241. 
[32] V. Bryk, O. Borodin, A. Kalchenko, V. Voyevodin, V. Ageev, A. Nikitina, V. Novikov, V. Inozemtsev, A. Zeman, F.A. Garner, in: Proceedings of Accelerator Applications, Bruges, Belgium, p. 1.

[33] F.A. Garner, M.B. Toloczko, B.H. Sencer, Journal of Nuclear Materials 276 (2000) 123142.

[34] M. Yamamoto, S. Ukai, S. Hayashi, T. Kaito, S. Ohtsuka, Journal of Nuclear Materials 417 (2011) 237-240.

[35] Y. Yazawa, T. Furuhara, T. Maki, ActaMaterialia 52 (2004) 3727-3736.

[36] J. He, F. Wan, K. Sridharan, T.R. Allen, A. Certain, V. Shutthanandan, Y.Q. Wu, Journal of Nuclear Materials 455 (2014) 41-45.

[37] J. Ribis, S. Lozano-Perez, Journal of Nuclear Materials 444 (2014) 314-322.

[38] Y. Miao, K. Mo, Z. Zhou, X. Liu, K.-C.Lan, G. Zhang, M.K. Miller, K.A. Powers, J. Almer, J.F. Stubbins, Materials Science \& Engineering A 625 (2015) 146-152.

[39] F.A. Garner, Journal of Nuclear Materials 117 (1983) 177-197.

[40] L. Shao, C.C. Wei, J. Gigax, A. Aitkaliyeva, D. Chen, B.H. Sencer, F.A. Garner, Journal of Nuclear Materials 453 (2014) 176-181.

[41] D. Chen, J. Wang, T. Chen, L. Shao, Scientific Reports 3 (2013).

[42] M. Song, Y. Wu, D. Chen, X. Wang, C. Sun, K.Y. Yu, Y. Chen, L. Shao, Y. Yang, K.T. Hartwig, X. Zhang, ActaMaterialia 74 (2014) 285-295.

[43] M. Song, C. Sun, J. Jang, C.H. Han, T.K. Kim, K.T. Hartwig, X. Zhang, Journal of Alloys and Compounds 577 (2013) 247-256.

[44] A.O.F. Hayama, H.R.Z. Sandim, J.F.C. Lins, M.F. Hupalo, A.F. Padilha, Materials Science \& Engineering A 371 (2004) 198-209.

[45] E. Nes, N. Ryum, O. Hunderi, ActaMaterialia 33 (1985) 11-22.

[46] T.R. Allen, J. Gan, J.I. Cole, S. Ukai, S. Shutthanandan, S. Thevuthasan, Nuclear Science and Engineering 151 (2005) 305-312. 
[47] Y. Chen, L. Jiao, C. Sun, M. Song, K.Y. Yu, Y. Liu, M. Kirk, M. Li, H. Wang, X. Zhang, Journal of Nuclear Materials 452 (2014) 321-327.

[48] K.C. Russell, Journal of Nuclear Materials 206 (1993) 129-138.

[49] M.-L. Lescoat, J. Ribis, Y. Chen, E.A. Marquis, E. Bordas, P. Trocellier, Y. Serruys, A. Gentils, O. Kaïtasov, Y. de Carlan, A. Legris, ActaMaterialia 78 (2014) 328-340.

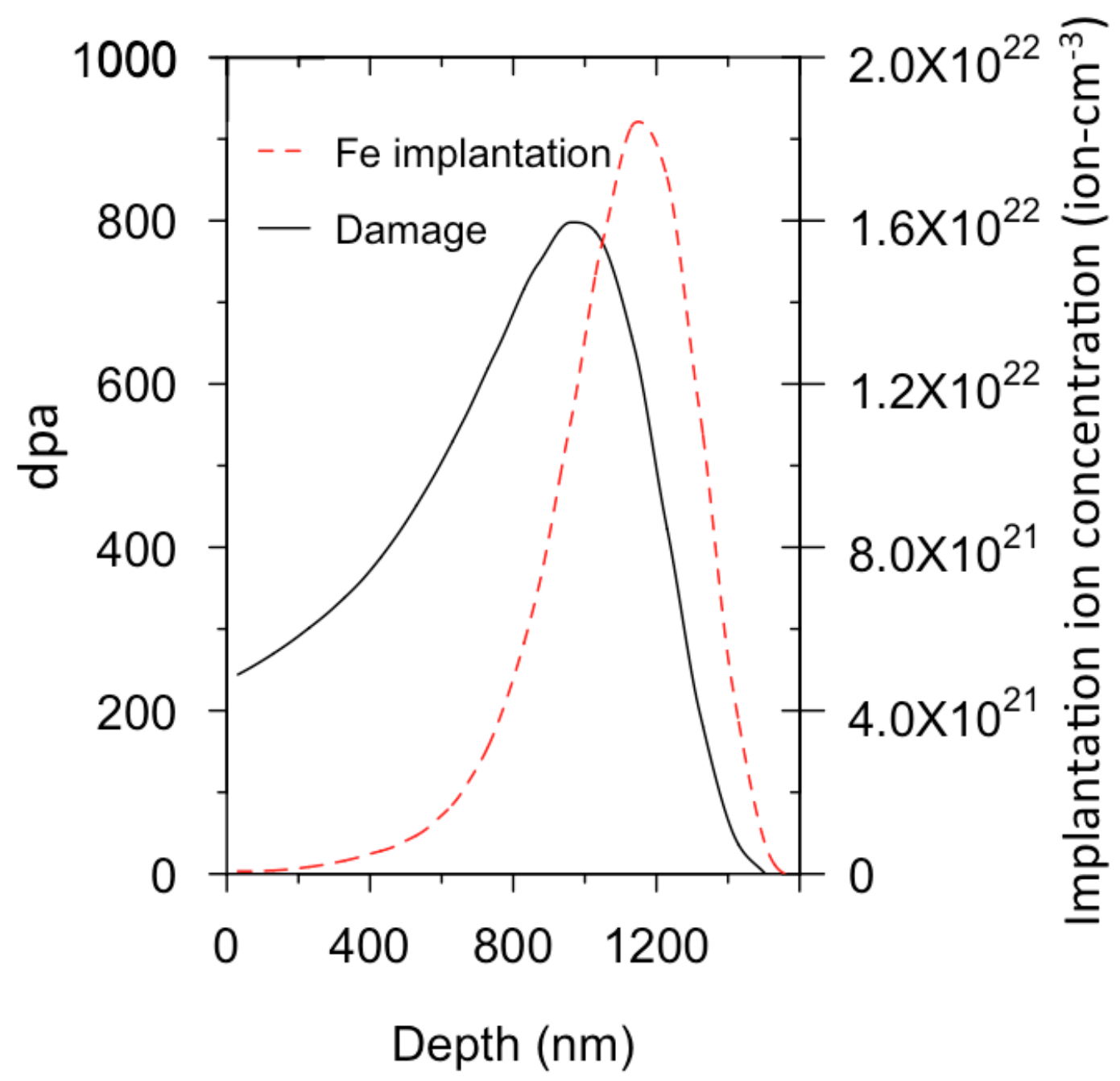

Figure 1: SRIM calculation of $3.5 \mathrm{MeV}$ self-ion irradiation into pure Fe to 800 dpa maximum, using a displacement threshold energy of $40 \mathrm{eV}$ and the Kinchin-Pease option 


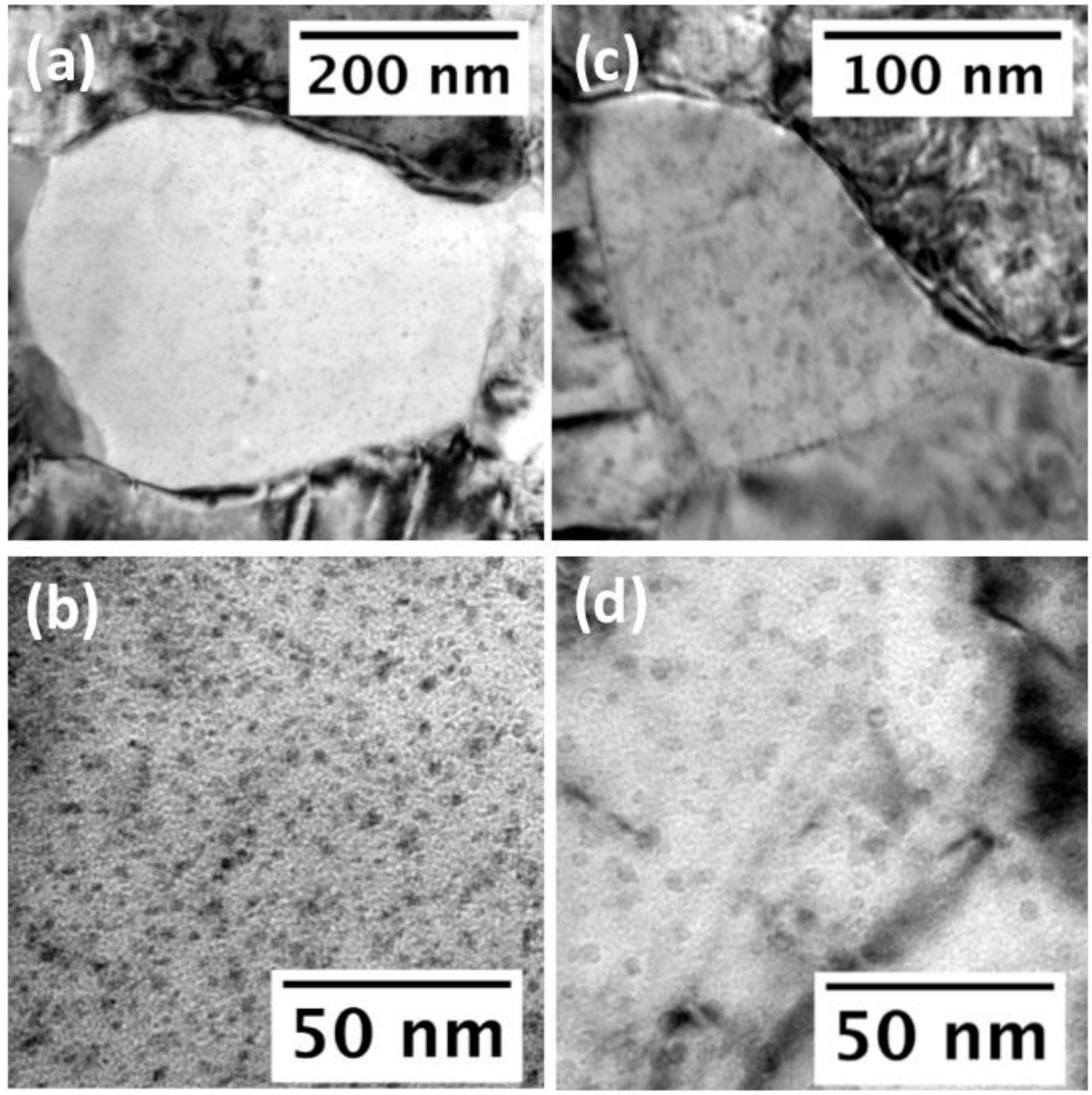

Figure 2: TEM micrographs of unirradiated samples having dispersoids in (a-b) a typical ferrite grain and (c-d) a typical tempered martensite grain. 


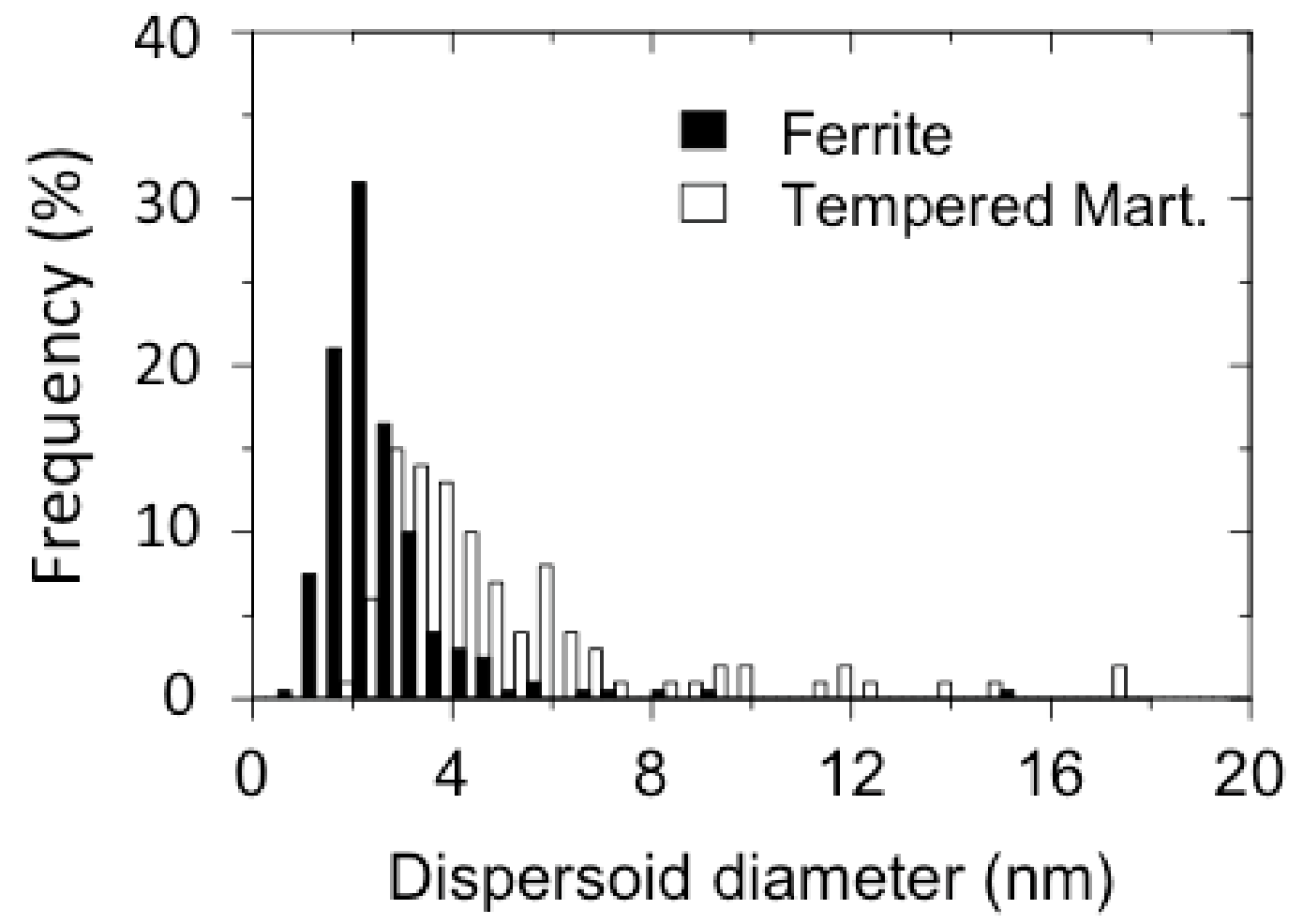

Figure 3: Size distribution of dispersoids in ferrite and tempered martensite grains in the before irradiation. 


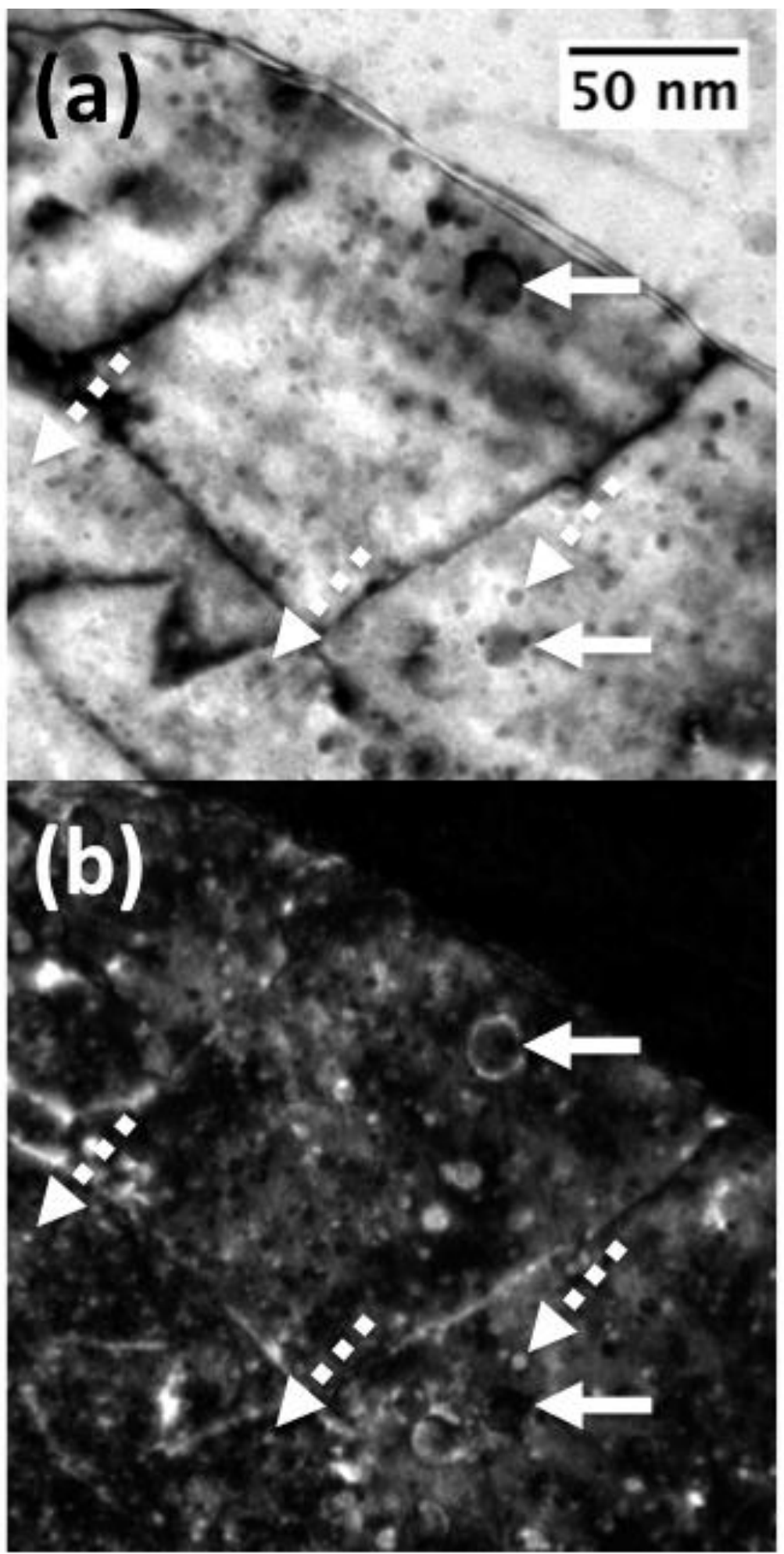

Figure 4: (a) Bright field TEM image and (b) weak beam dark field TEM image of an unirradiated tempered martensitic grain obtained near $\mathbf{g}_{110}$. 


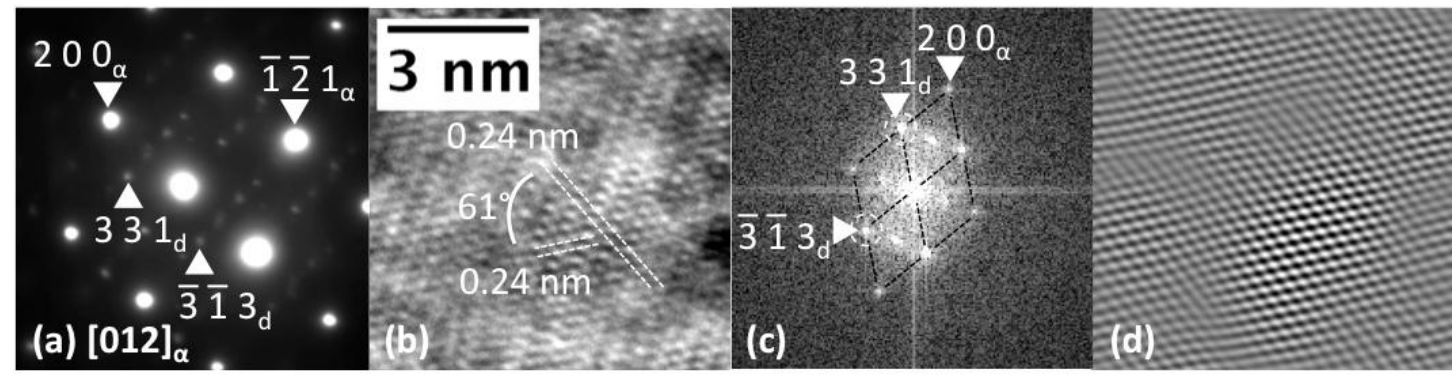

Figure 5: (a) Diffraction pattern of an unirradiated ferrite grain, (b) HRTEM micrograph of a dispersoid in this grain, (c) FFT diagram of the micrograph in (b), (d) FFT filtered image derived from diffraction spots circled in (c). 


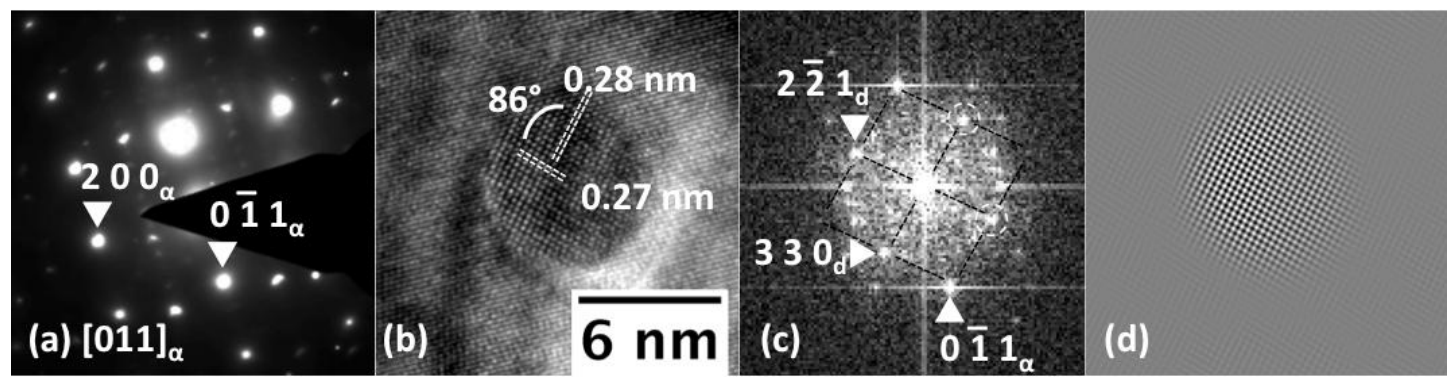

Figure 6: (a) Diffraction pattern of an unirradiated tempered martensite grain, (b) HRTEM micrograph of andispersoid in this grain, (c) FFT diagram of the micrograph in (b), (d) FFT filtered image derived from diffraction spots circled in (c). 


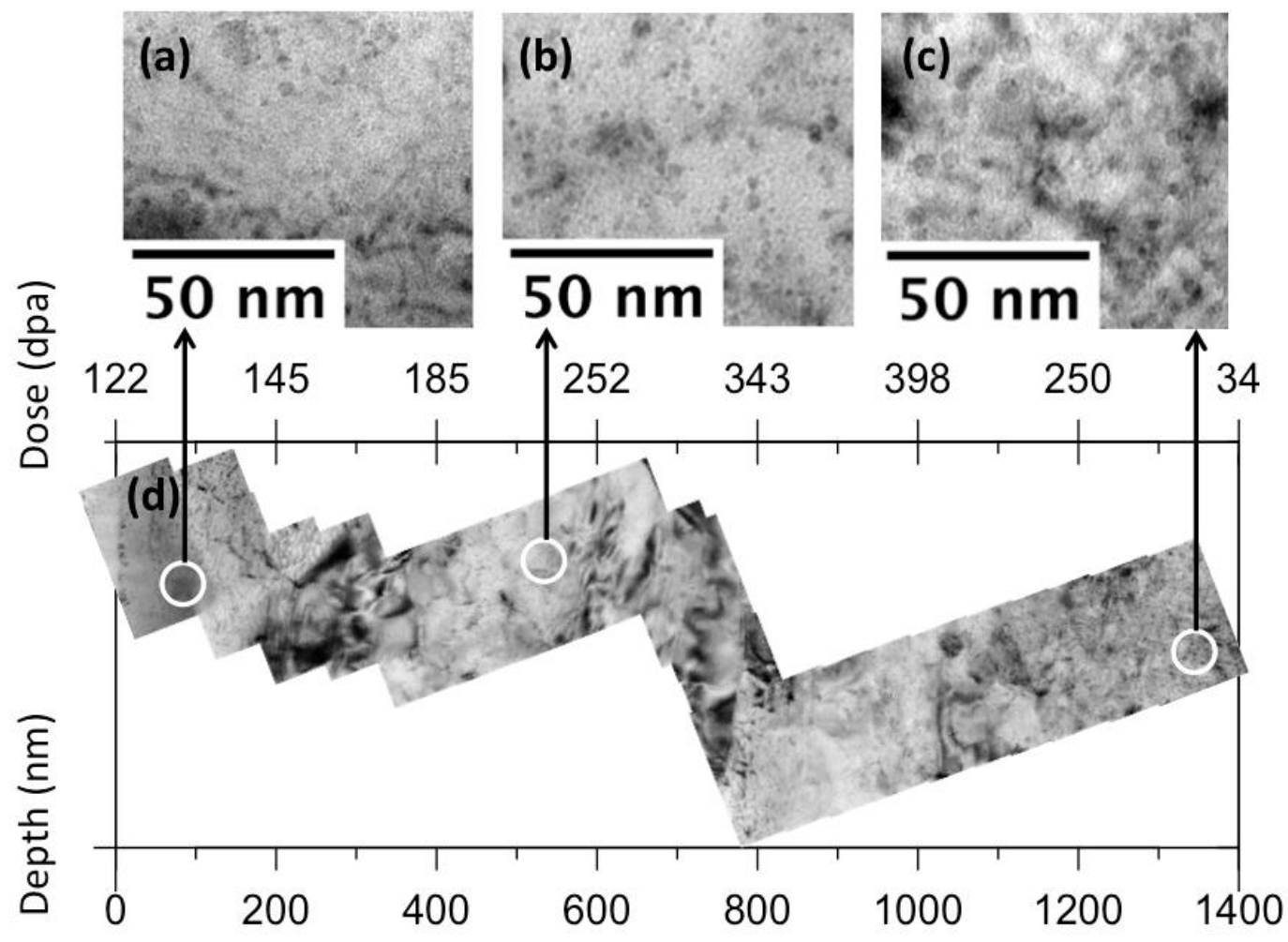

Figure 7: (a-c) TEM micrographics at near surface region, half-peak-dpa region and end of irradiation region, respectively, and (d) panoramic TEM micrographs from the 400 peak dpa sample. 


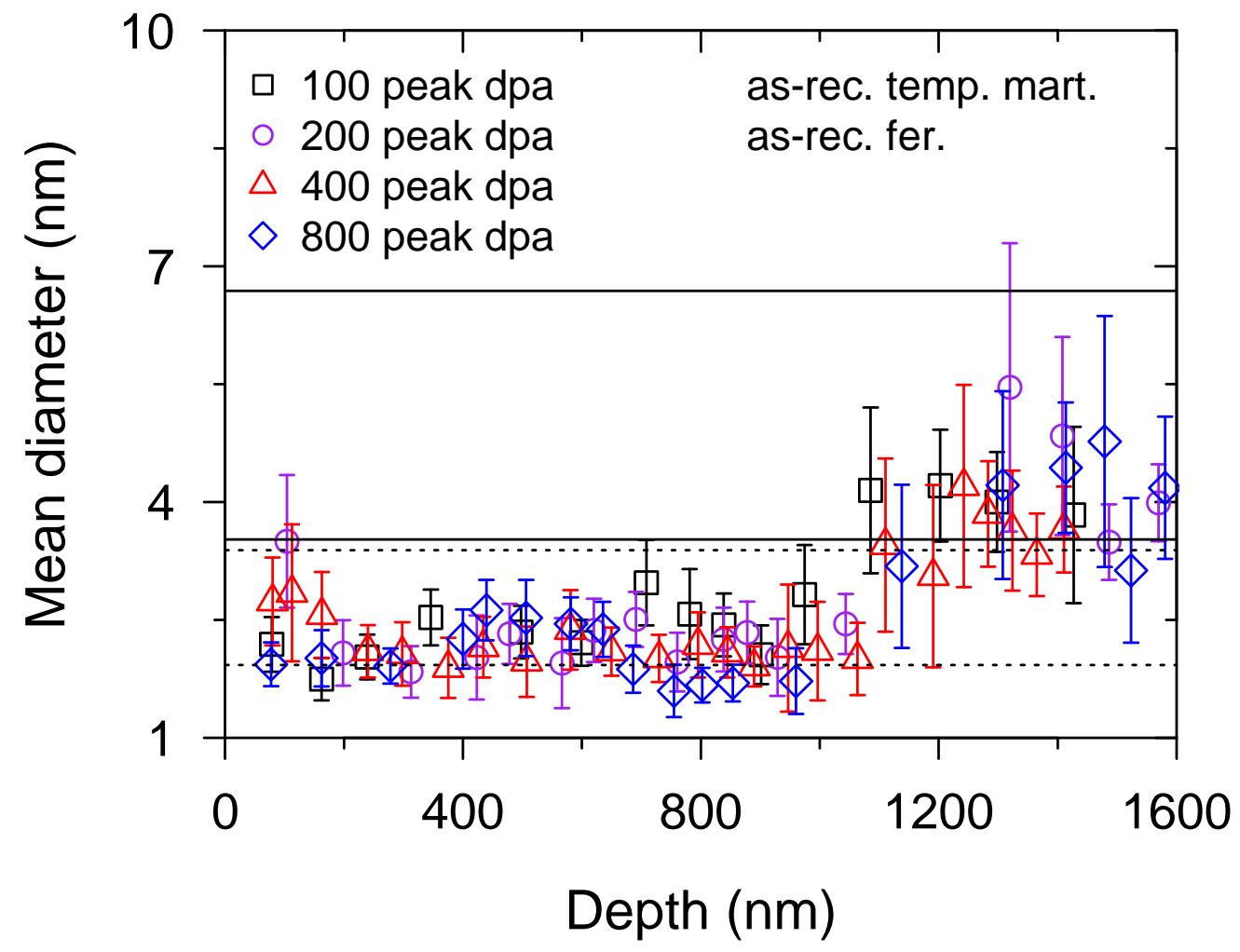

Figure 8: Mean dispersoid diameter vs. depth from samples irradiated up to peak dpa values of $100,200,400$ and 800, with solid horizontal lines representing the range of the as-received dispersoid distribution in tempered martensite grains, and the dashed horizontal lines representing the range of the as-received dispersoid distribution in ferrite grains. 

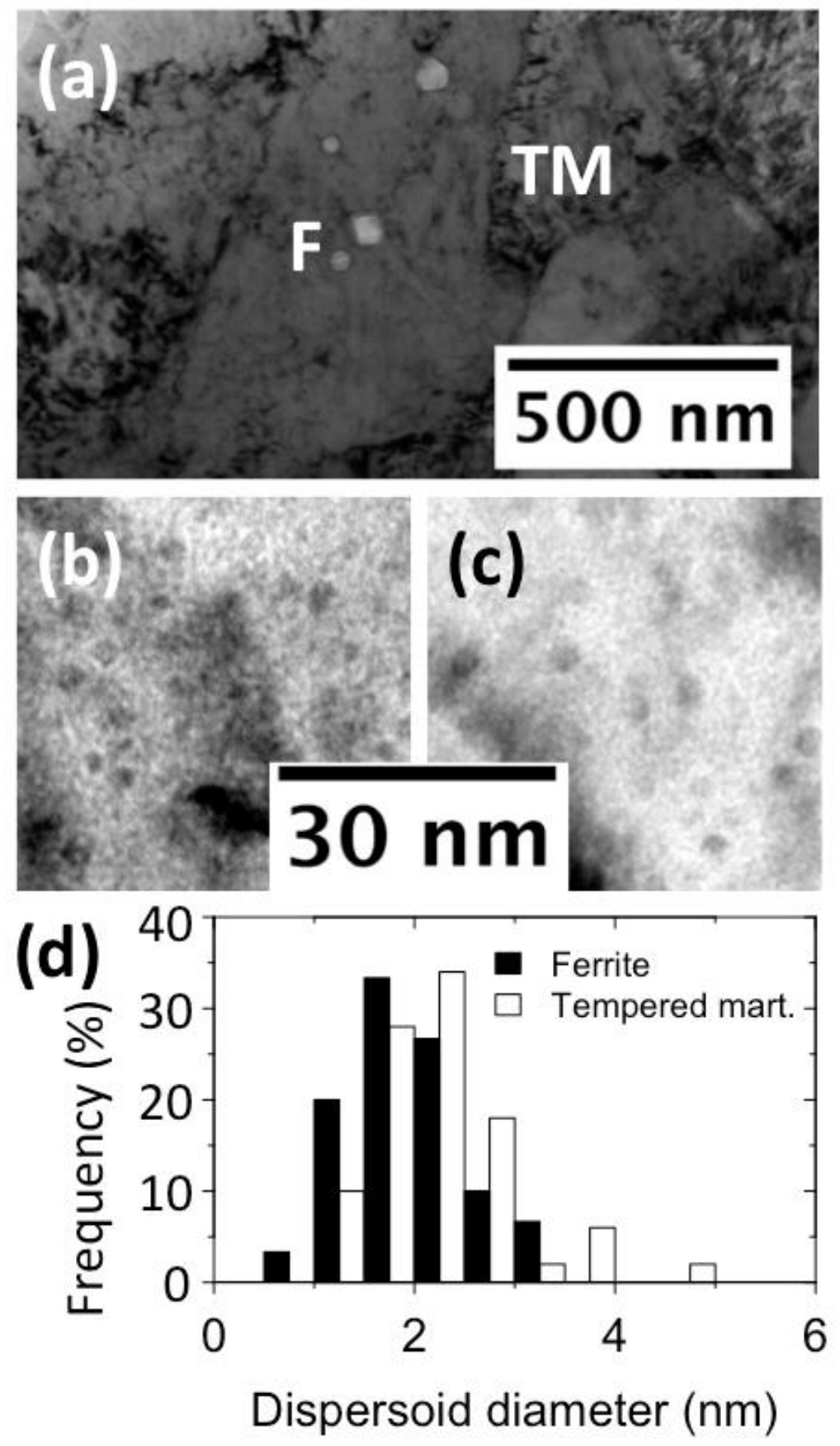

Figure 9: (a) TEM micrograph taken from the 500-1200 nm region of the 800 peak dpa sample, with F and TM referring to ferrite and tempered martensite phase, respectively, and (b), dispersoids in the ferrite grain F, and (c), dispersoids in the tempered martensite grain TM, and (d), statistic size distributions of dispersoids in irradiated ferrite and tempered martensite phases. 


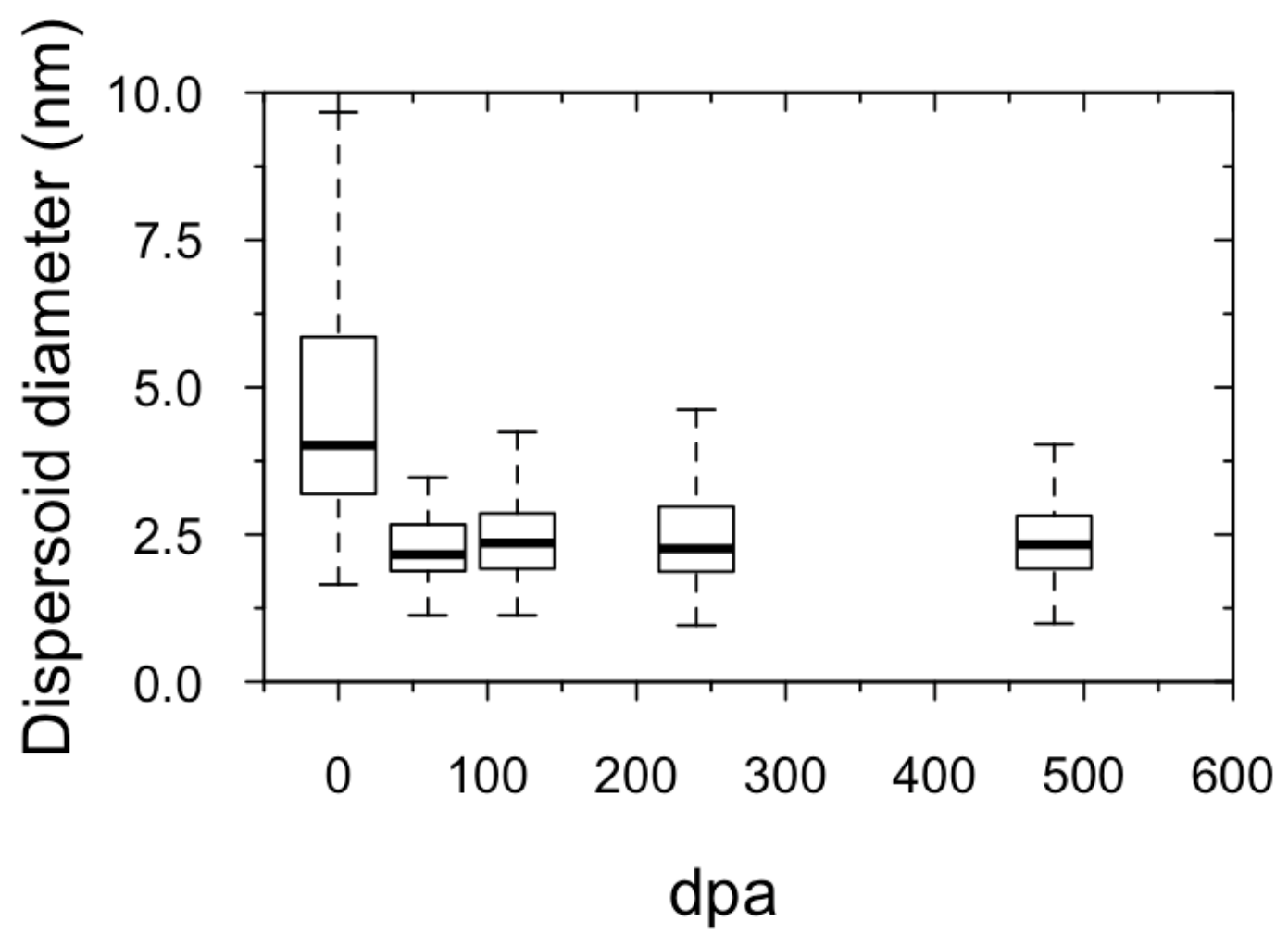

Figure 10: Dispersoid size as a function of increasing dpa in tempered martensite grains, with the bottom and top of the rectangular boxes represents the first and third quartiles of the statistic data, respectively, while the bar in the middle of the box represents the mean value. 

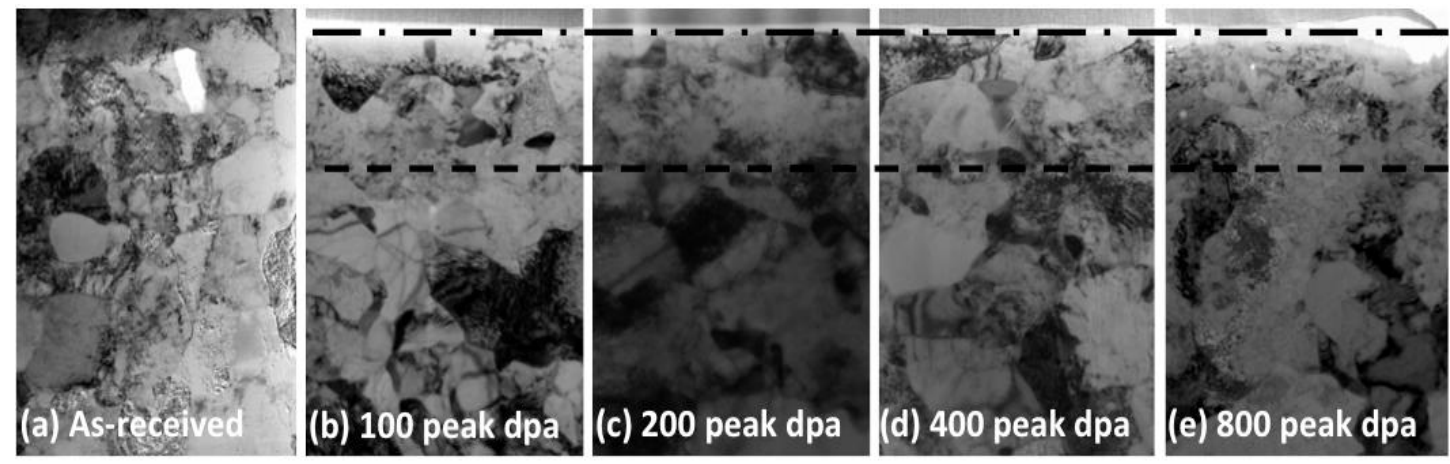

$\overline{1 \mu \mathrm{m}} \quad \cdot-\cdot-$ Irradiation surface $\quad----$ Peak dpa depth

Figure 11: Bright field cross-sectional TEM micrographs of (a) unirradiated sample and (b-e) samples irradiated to $100,200,400$ and 800 peak dpa, respectively. The dashed lines refer to the irradiated region. 


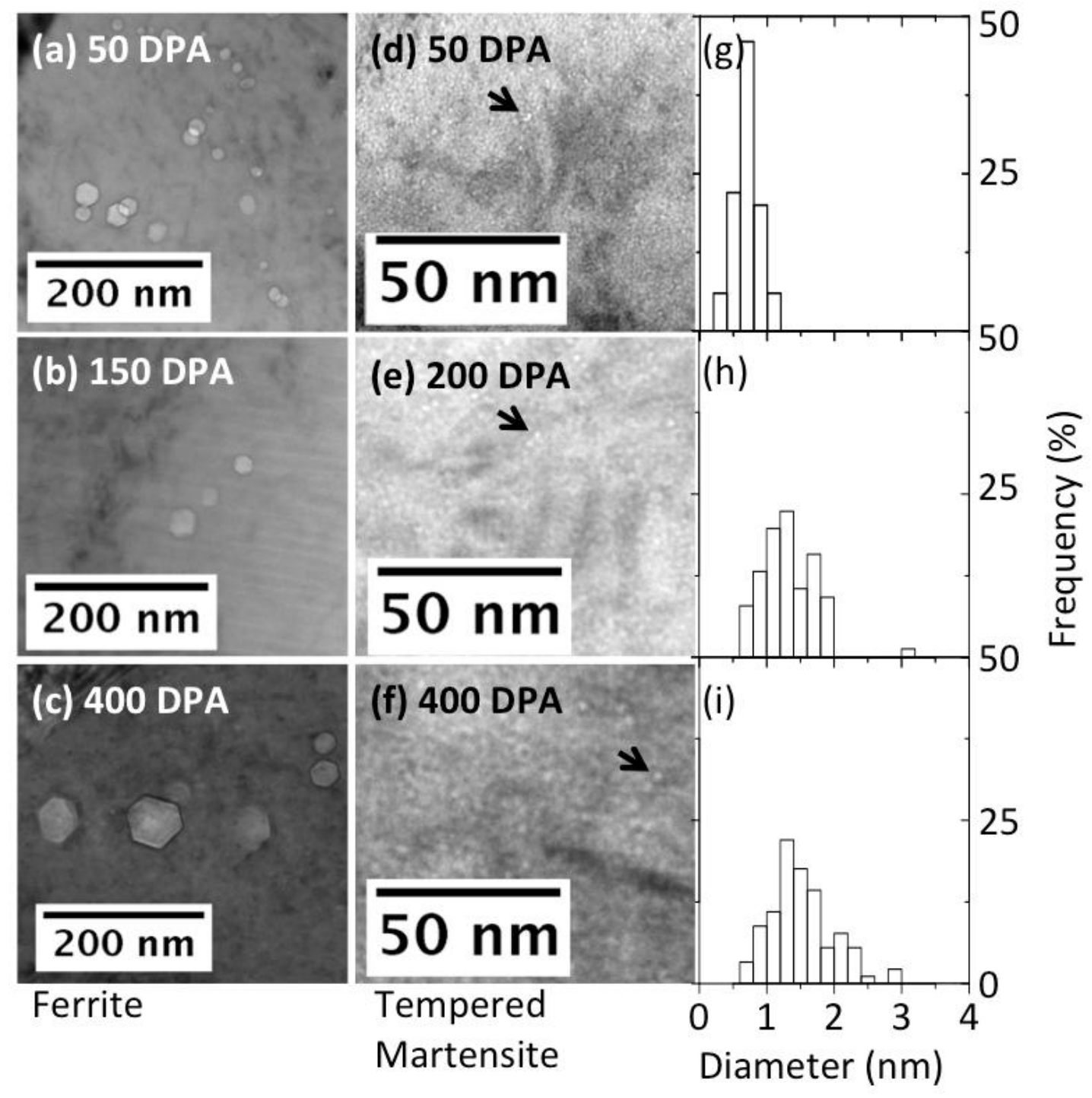

Figure 12: (a)-(c) TEM micrographs obtained at the depth of $500 \mathrm{~nm}$ in ferrite phases after 100, 300, 800 peak dpa irradiation, respectively, and (d-f) TEM micrographs obtained at the depth of $500 \mathrm{~nm}$ in tempered martensite phase after 100, 300, 800 peak dpa irradiation, respectively, with arrows highlighting some of the nano-cavities, and $(g, h, i)$ the size distributions of nano-cavity in tempered martensite phases after irradiation corresponding to $(\mathrm{d}, \mathrm{e}, \mathrm{f})$. 
(a) Ferrite

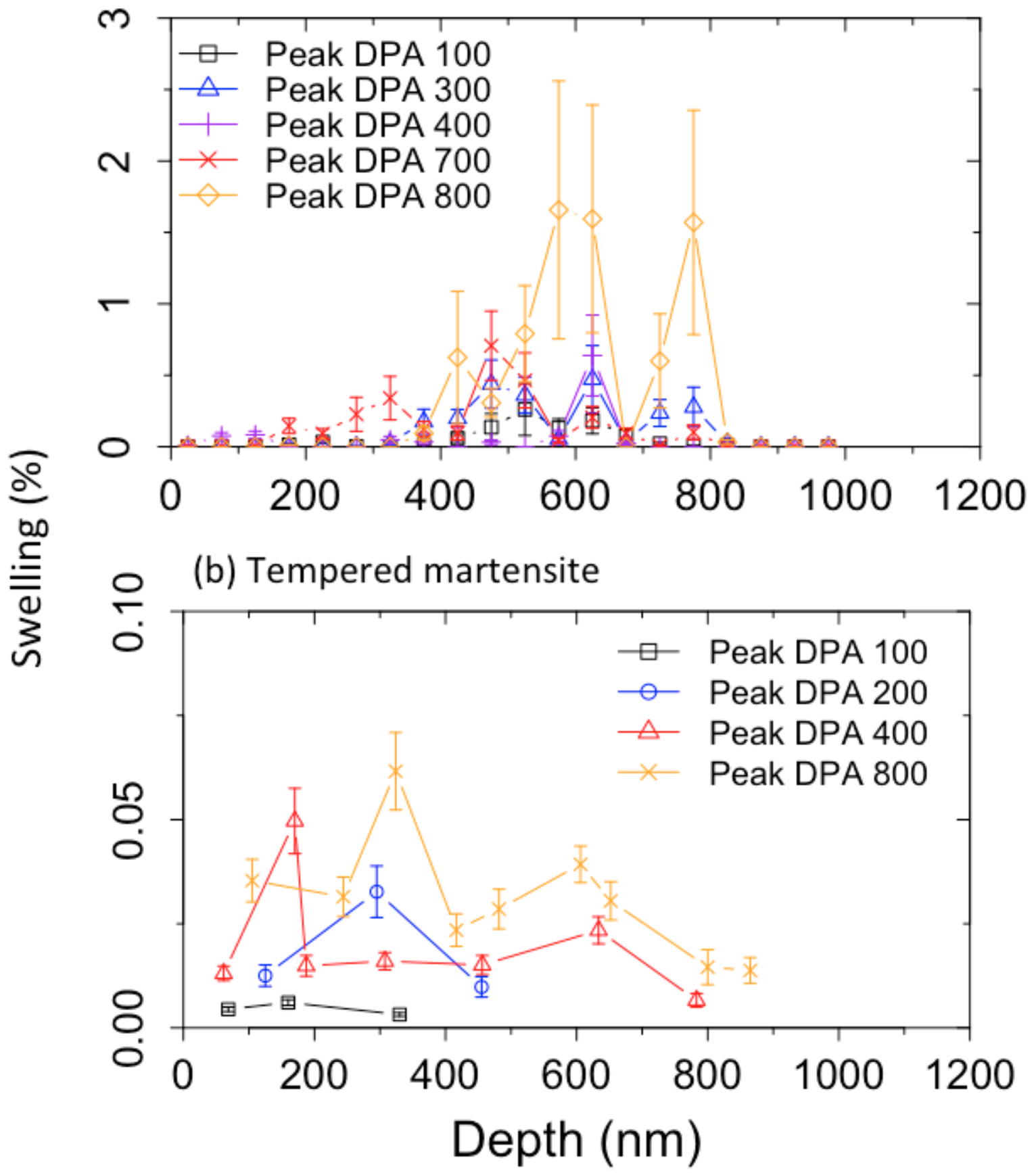

Figure 13: Swelling vs. depth distributions in (a) ferrite and (b) tempered martensite at different peak dpa levels. 


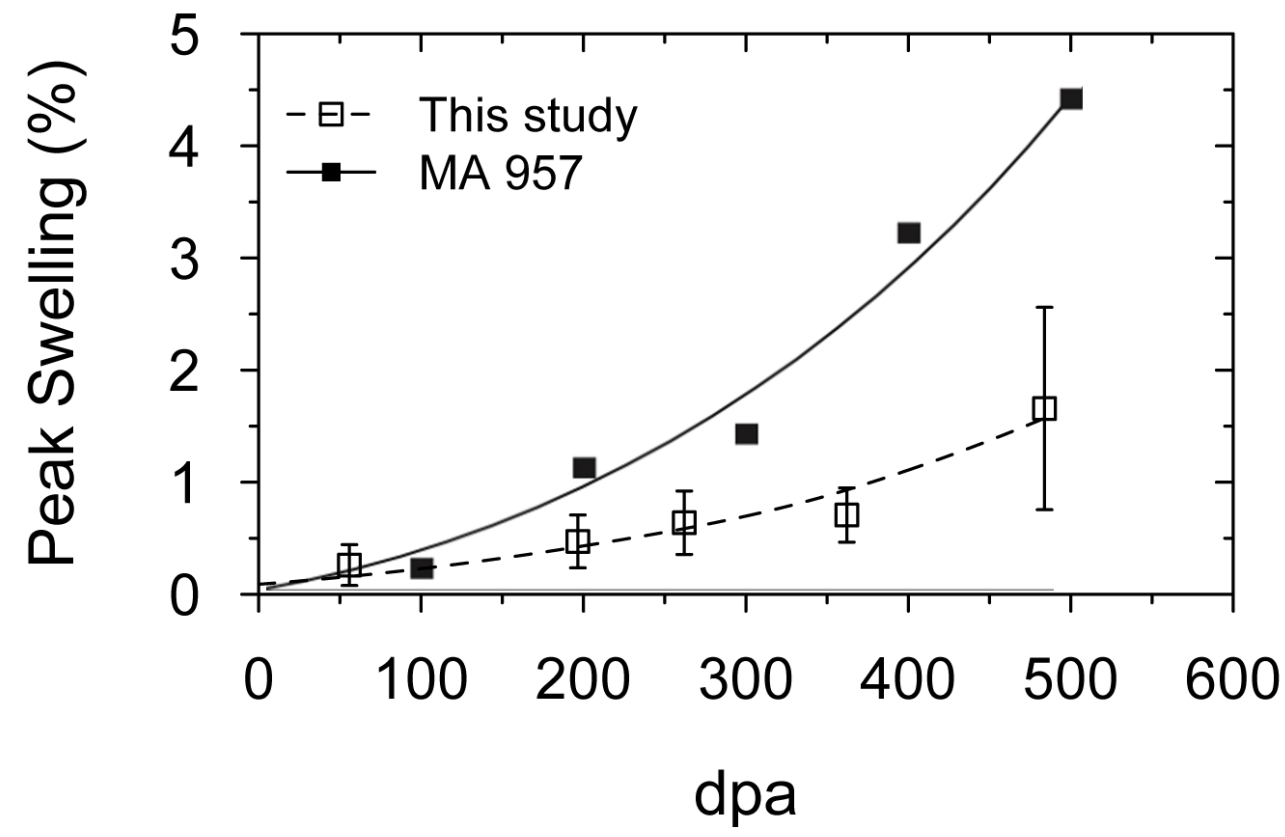

Figure 14: Maximum swelling as a function of local dpa in ferrite phase, in a comparison with swelling of s of ferritic MA957 [10] 


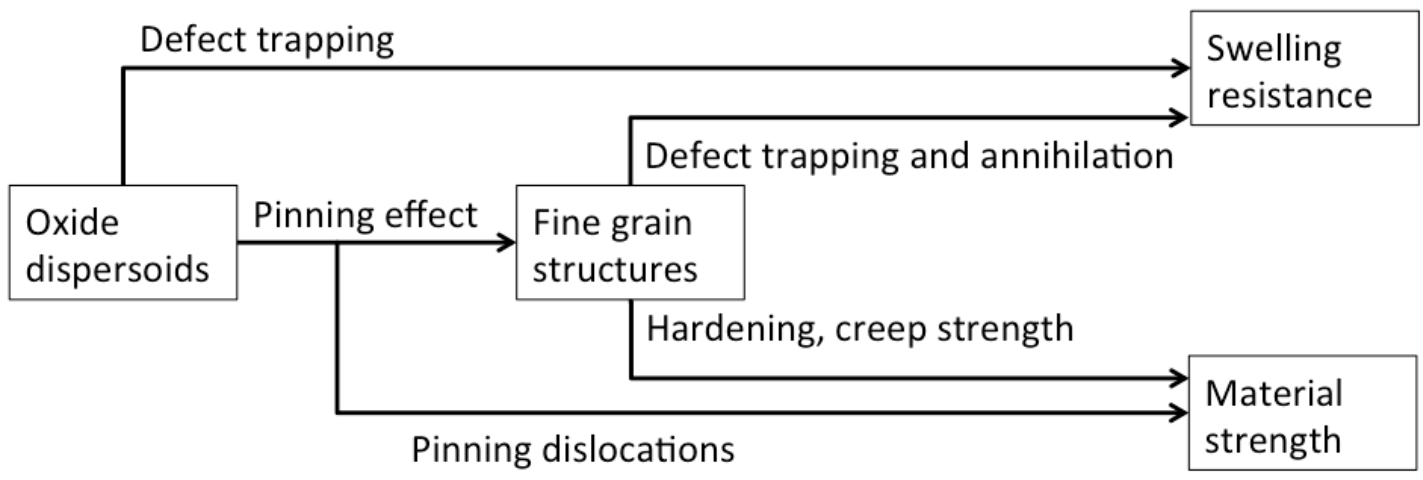

Figure 15: Schematic showing mechanisms of dispersoid effects on void swelling and mechanical properties. 
Table 1: Composition of the as-received 12Cr dual-phase ODS alloy

\begin{tabular}{lllllllllll} 
Component: & $\mathrm{Fe}$ & $\mathrm{C}$ & $\mathrm{Cr}$ & $\mathrm{Ni}$ & $\mathrm{W}$ & $\mathrm{Ti}$ & $\mathrm{N}$ & $\mathrm{Ar}$ & $\mathrm{Y}_{2} \mathrm{O}_{3}$ & Excess O \\
Weight: & 85.74 & 0.16 & 11.52 & 0.34 & 1.44 & 0.28 & 0.007 & 0.006 & 0.36 & 0.144 \\
\hline
\end{tabular}


Table 2: Mean grain size measured in as-received, irradiated and thermal-aged irradiation-free conditions

\begin{tabular}{lllll}
\hline As-received sample & $274 \pm 65$ & \multicolumn{3}{c}{ Unit: $\mathrm{nm}$} \\
\hline Location in sample & 100 peak dpa & 200 peak dpa & 400 peak dpa & 800 peak dpa \\
\hline Peak dpa region & $281 \pm 61$ & $271 \pm 51$ & $309 \pm 40$ & $268 \pm 44$ \\
Irradiation free region & $272 \pm 46$ & $293 \pm 62$ & $282 \pm 46$ & $241 \pm 53$ \\
\hline
\end{tabular}

